\title{
制がん性白金錯体シスプラチンのイオン交換体への 保持挙動
}

\author{
木津 良一 ${ }^{\circledR}$, 宮崎 元一 ${ }^{*}$
}

(1989 年 12 月 28 日受理)

\section{1 緒言}

白金錯体のシスプラチン \{cis-ジクロロジアンミン白 金(II)，CDDP $\}$ は優れた制がん率として広く臨床に用 いられており", 今後, CDDP の体内動態を詳細に検討 する必要がある.なかでも制がん作用の発現に密接に関 連していると考えられる未変化錯体, すなわち CDDP, の体内動態の追求が重要であり, 生体試料中 CDDP の 分析法の確立にむけて HPLC による方法が種々検討さ れている2) ${ }^{20)}$.

CDDP は電荷を持たない無機の錯体であるが，この ような錯体の HPLC 挙動はほとんど知見が得られてお らず, 従来, CDDP を 2 以上の保持容量比で保持する カラムは知られていなかった。 そのため血しょう及び尿 中の GDDP の分析においては共存成分との分離は悪 く, CDDP のできるだけ選択的な検出法の開発に主眼 が置かれたが2) 8), 検出器としてオフラインでの原子 吸光光度計 ${ }^{23)}$, つり下げ型水銀滴電極を備えたポーラ

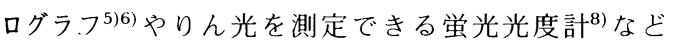
HPLC 用検出器としては必ずしも一般的でない検出器 を必要とし, GDDP の体内挙動研究に活用され得る方 法にはいたらなかった。一方, 著者らがこれまで行って きた血しょう及び尿中 CDDP の HPLC 分析法につい ての研究から, CDDP が幾つかの陰イオン交換及び陽 イオン交換カラムで強く保持されることを見いだすと共 に，この性質を利用して血しょう及び尿中 CDDP の

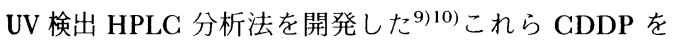
強く保持するイオン交換カラムにおける保持・溶出挙動 の特徵を明らかにできれば, 血しょう及び尿成分之 CDDP の分離を改善するうえで有用であり, 更に高感 度ではん用性の高い HPLC 分析法の開発につながると

\footnotetext{
*金沢大学薬学部 : 920 石川県金沢市宝町 13-1
}

考えられた。

そこで本研究では, 今後 GDDP のより高感度ではん 用性の高い分析法の開発研究に資する目的で，イオン交 換力ラムを用いる HPLC における CDDP の挙動を検 討した結果, 興味深い知見が得られたので報告する.

\section{2 実験}

\section{$2 \cdot 1$ 試 薬}

CDDP 及び trans- ジクロロジアンミン白金 (II) (TDDP) は Aldrich Chemical Co. から購入した. cis-ジ ブロモジアンミン白金(II)(CBrP), trans-ジブロモジア ンミン白金(II) (TBrP), cis-ジヨードジアンミン白金 (II)（CIP）及び trans-ジヨードジアンミン白金(II)

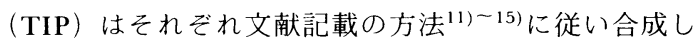
た。 CDDP 及び TDDP は $0.15 \mathrm{M}$ 塩化ナトリウム溶液 に， $\mathrm{CBrP}$ 及び $\mathrm{TBrP}$ は $0.10 \mathrm{M}$ 臭化ナトリウム溶液 に, CIP 及び TIP は $0.10 \mathrm{M} ヨ$ ヨ化ナトリウム溶液に それぞれ $0.2 \mathrm{mM}$ となるように溶解し, 溶離液にて適 宜希釈して使用した。

イオン交換カラムは，三菱化成製のイオン交換充てん 戍を上昇法にてスラリ一充てんして作製し，使用した。

\section{$2 \cdot 2$ HPLC}

HPLC 装置は, 島津 LC-5A ポンプ,レオダイン 7125 試料注入器, 島津 CTO-2A カラム恒温槽, 島津 SPD-2A 紫外吸収検出器及びバントス U-288 記録計で 構成した。流量は $1 \mathrm{ml} / \mathrm{min}$, カラム温度は $40^{\circ} \mathrm{C}$, 試料 注入量は $100 \mu \mathrm{l}$ とし, 検出波長は主として $210 \mathrm{~nm}$ を 用いた。

\section{3 結果及び考察}

\section{3・1 各種カラムにおける CDDP の保持容量比}

各種カラムにおける CDDP の保持容量比を Table 1 に示す. CDDP ははイオン交換基を持たない逆相分配 
系のカラムには保持されなかったが，イオン交換カラム ではいずれのカラムにも保持された，従来は 2 以上の 保持容量比を与えるカラムは知られていなかったが, 陰 イオン交換及び陽イオン交換の各モ一ドにおいて, イオ ン交換容量が大きいカラムで保持容量比もより大きく, MCI GEL CA10S力ラムでは 30 以上の保持容量比が得 られた。

更に本研究では, イオン交換カラムを用いる HPLC における CDDP の挙動を理解するうえで有用な知見が 得られることを期待して, CDDP の類似化合物の TDDP, GBrP, TBrP, GIP 及び TIP についても検討し たところ，これら錯体も陰イオン及び陽イオン交換力ラ ムに保持されるなど, CDDP と同様の挙動を示すこと が明らかになった。

検討した白金錯体の保持容量比がカラムのイオン交換

Table 1 Capacity factors of CDDP on various columns

\begin{tabular}{ccc}
\hline $\begin{array}{c}\text { Column } \\
\text { (chromatographic } \\
\text { mode) }\end{array}$ & $\begin{array}{c}\text { Ion exchange } \\
\text { capacity } \\
\text { (mequiv/ml) }\end{array}$ & $\begin{array}{c}\text { Capacity } \\
\text { factor }\end{array}$ \\
\hline (Anion exchange) & & \\
MCI GEL SCA01 & 0.01 & 0.6 \\
MCI GEL CDR10 & 0.3 & 16.0 \\
MCI GEL CA10S & 1.2 & 31.9 \\
(Cation exchange) & & 0.1 \\
MCI GEL SCK01 & 0.01 & 1.4 \\
MCI GEL CK10S & 2.0 & $<0.1$ \\
(Reversed-phase partition) & - & $<0.1$ \\
HITACHI GEL \#3010 & - & \\
COSMOSIL 5C18 & - & \\
\hline
\end{tabular}

Eluent : $0.1 \mathrm{M} \mathrm{NaH}_{2} \mathrm{PO}_{4}$; CDDP : cis-dichlorodiammine platinum(II)
容量に依存することから，これら錯体の保持にはイオン 交換基が関与していると考えられた.

そこで次に, 種々の溶離液を用いて保持容量比を検討 した。分離カラムには, 陰イオン交換の MCI GEL

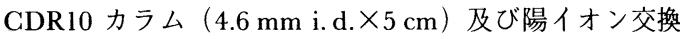
の MCI GEL CK10S カラム $(4.6 \mathrm{~mm}$ i.d. $\times 25 \mathrm{~cm})$ を 用いた。 CDDP 及び類似白金錯体の保持容量比を Table 2 に示す. 又一例として, CDDP, CBrP 及び CIP について過塩素酸ナトリウム溶離液で得られたク ロマトグラムを Fig. 1 に示す.

検討したいずれのカラムと溶離液の組み合わせにおい ても，各錯体の保持容量比は, クロロ錯体くブロモ錯体 くヨード錯体の順で大きくなった，又異性体間の比較で は，トランス体に比ベシス体で大きくなった。一方，い ずれの溶離液においても, 溶離液濃度を変化させても各 錯体の保持容量比はほとんど変化せず，更に $\mathrm{pH}$ にも 依存しないなど極めて特異な挙動を示した。

$\mathrm{Pt}(\mathrm{II}) \mathrm{X}_{2} \mathrm{~L}_{2}$ （X：クロロ，ブロモ，ヨードなど， L : アンモニア，トリエチルホスフィンなど）型の白金 （II）錯体の双極子モーメントは，トランス異性体に比 ベシス異性体で大き( ${ }^{11) 12)}$ が, 本研究でも保持容量比 はトランス異性体に比ベシス異性体で大きい. 又分子内 のハロゲン基によっても大きく変化することから， CDDPをはじめとして本研究で用いた白金錯体のイオ ン交換カラムへの保持には, 錯体の静電的特性が重要な 役割を担っていると推定される.

\section{$3 \cdot 2$ 保持される際のイオン交換反応}

上記 $3 \cdot 1$ の結果から, CDDP がイオン交換カラムに 保持される際には，イオン性物質におけるようなイオン 交換反応は起きていない可能性がある．そこで，近年発 展しつつある吸光度検出イオンクロマトグラフィ一の概

Table 2 Capacity factors of CDDP and its five analogues with various eluents

\begin{tabular}{|c|c|c|c|c|c|c|c|}
\hline \multirow{2}{*}{ Column } & \multirow{2}{*}{ Elueut } & \multicolumn{6}{|c|}{ Capacity factor } \\
\hline & & TDDP & CDDP & $\mathrm{TBrP}$ & $\mathrm{CBrP}$ & TIP & CIP \\
\hline \multirow{3}{*}{$\begin{array}{l}\text { MCI GEL CDR10 } \\
\text { (Anion exchange) }\end{array}$} & $\mathrm{NaClO}_{4}$ & 1.0 & 1.3 & 5.5 & 14.0 & 34.9 & 89.5 \\
\hline & $\mathrm{NaCl}$ & 1.8 & 7.8 & 7.5 & 34.0 & 51.7 & $>150$ \\
\hline & $\mathrm{NaH}_{2} \mathrm{PO}_{4} \cdot 2 \mathrm{H}_{2} \mathrm{O}$ & 1.5 & 16.0 & 9.3 & 55.0 & 79.4 & $>150$ \\
\hline MCI GEL CKIOS & $\mathrm{NaH}_{2} \mathrm{PO}_{4} \cdot 2 \mathrm{H}_{2} \mathrm{O}$ & 1.0 & 1.4 & 1.7 & 2.5 & 10.3 & 18.6 \\
\hline (Cation exchange) & $\mathrm{KH}_{2} \mathrm{PO}_{4}$ & 1.7 & 2.1 & 2.5 & 3.5 & 15.4 & 24.0 \\
\hline
\end{tabular}

Column size : MCI GEL CDR10; $4.6 \mathrm{~mm}$ i.d. $\times 5 \mathrm{~cm} ;$ MCI GEL CK10S; $4.6 \mathrm{~mm}$ i.d. $\times 25 \mathrm{~cm}$. Eluent concentration : $0.1 \mathrm{M}$. TDDP : trans-dichlorodiammine platinum(II); GBrP : cis-dibromodiammine platinum(II); TBrP : trans-dibromodiammine platinum(II) ; CIP : cis-diiododiammine platinum(II) ; TIP : trans-diiododiammine platinum(II) 

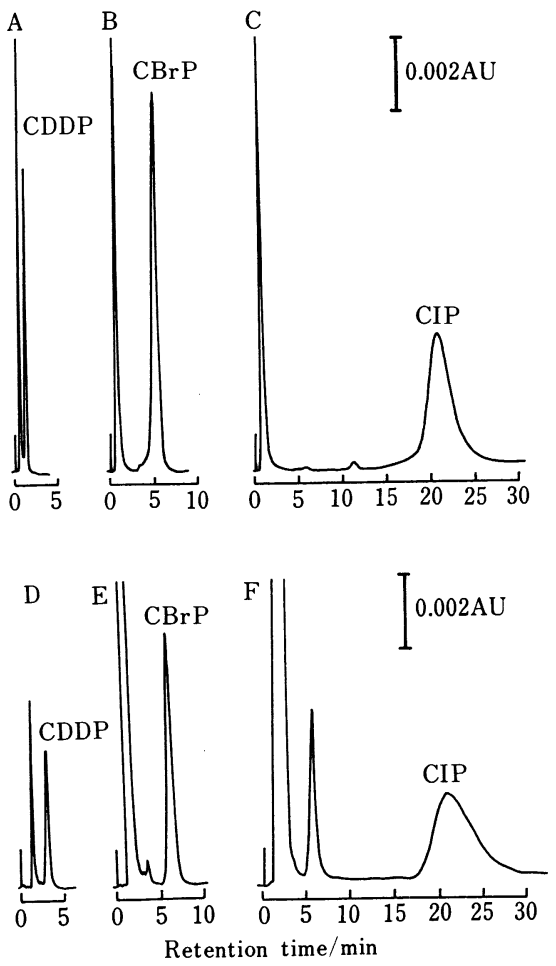

Fig. 1 Typical chromatograms of CDDP, $\mathrm{CB}_{\mathrm{r}} \mathrm{P}$ and CIP on MCI GEL CDR 10 column and MCI GEL CK $10 \mathrm{~S}$ column

A, B and C: MCI GEL CDR 10 column (4.6 $\mathrm{mm}$ i.d. $\times 5 \mathrm{~cm}$, anion exchange); D, E and $\mathrm{F}$ : MCI GEL GK $10 \mathrm{~S}$ column $(4.6 \mathrm{~mm}$ i.d. $\times 25$ cm, cation exchange), Eluent: $0.1 \mathrm{M} \mathrm{NaClO}_{4}$ $10 \mu \mathrm{M}$ solution of each $\mathrm{Pt}(\mathrm{II})$ complex was subjected to HPLC

念を用いてこの可能性を検討した.

吸光度検出イオンクロマトグラフィ一の概念について は成書 ${ }^{16)}$ に詳述されているが，イオン交換クロマトグ ラフィ一では, 試料イオンの溶出に伴いその当量分だけ 溶離液イオン濃度が減少するので, クロマトグラム上の シグナルは, 試料イオンに基づく吸光度が溶離液イオン 濃度の減少に伴う吸光度の減少に相殺されたものであ る. 従って, 溶離液イオンが UV 吸収を示す場合と示 さない場合で, CDDP の検出波長-ピーク高さプロフィ ルを比較することにより，上記の可能性を検討できると 考えた。

$\mathrm{UV}$ 吸収を示さない溶離液にはリン酸一ナトリウム, UV 吸収を示す溶離液には硝酸ナトリウム, フタル酸二 ナトリウム及びイミダゾールの各溶液を用いた． 220
Table 3 Relative peak heights of CDDP at various wavelengths

\begin{tabular}{cccccc}
\hline \multirow{2}{*}{ Eluent } & \multicolumn{5}{c}{ Relative peak height } \\
\cline { 2 - 6 } & $210 \mathrm{~nm}$ & $220 \mathrm{~nm}$ & $230 \mathrm{~nm}$ & $250 \mathrm{~nm}$ & $300 \mathrm{~nm}$ \\
\hline$(1)$ & 34.8 & 15.5 & 5.7 & 0.2 & $\mathbf{1}$ \\
$(2)$ & 29.8 & 15.0 & 5.4 & 0.2 & $\mathbf{1}$ \\
$(3)$ & 33.4 & 15.3 & 6.4 & 0.3 & $\mathbf{1}$ \\
$(4)$ & 31.2 & 14.8 & 5.4 & 0.2 & $\mathbf{1}$ \\
\hline
\end{tabular}

(1) $50 \mathrm{mM}$ sodium dihydrogen phosphate; (2) 0.2 $\mathrm{mM}$ sodium nitrate; (3) $0.01 \mathrm{mM}$ disodium phthalate; (4) $0.1 \mathrm{mM}$ imidazole. Eluents (1), (2) and (3) were used for anion exchange chromatography with a MCI GEL CDR 10 colum $(4.6 \mathrm{~mm}$ i.d. $\times$ $5 \mathrm{~cm}$ ). Eluents (1) and (4) were used for cation exchange chromatography with a MCI GEL CK10S colum $(4.6 \mathrm{~mm}$ i.d. $\times 25 \mathrm{~cm})$. The $\mathrm{pH}$ of imidazole eluent was adjusted to 4.1 with phosphoric acid.

$\mathrm{nm}$ 及び $210 \mathrm{~nm}$ におけるモル吸光係数はそれぞれ, CDDP で 2400, 5300, リン酸一ナトリウムでは 10 以 下, 硝酸ナトリウムで 3200,7700 , フタル酸二ナトリウ ムで 9300,18000, イミダゾールで 1700,5600 であっ た.

Table 3 には, 各溶離液について $300 \mathrm{~nm}$ でのピーク 高さを 1 とした相対ピーク高さを示す. 相対ピーク高 さは溶離液が UV 吸収を示す場合と示さない場合で差 はなく, GDDP がイオン交換カラムに保持される際に はイオン交換反応は起きていないことが明らかになっ た. CDDP がイオン交換カラムに保持される機構の一 つとして, CDDP とイオン交換基の間の双極子-イオン 相互作用が考えられた.

緒言にも述べたように, 従来 CDDP について 2 以上 の保持容量比を与える HPLC システムが知られておら ず，血しょう及び尿成分と CDDP の分離が悪かったた め, CDDP に選択的な検出法が研究されてきたが, 体 内挙動研究にはん用するには十分でなかった.もし, 生 体試料中の成分と CDDP の分離を良くすることができ れば, UV 検出器や電気化学検出器など市販の HPLC 用検出器を用いても血しょう及び尿中の CDDP を高感 度に分析できる可能性がある．この点から本研究で見い だされたイオン交換カラムを用いる HPLCにおける CDDP の挙動は, 今後, 更に高感度ではん用性の高い 生体試料中 CDDP のHPLC 分析法を開発するうえで有 用な知見となるものと考える.

本研究の費用の一部は, 文部省科学研究費補助金によ った. 又, 本研究で MCI GEL の使用に御便宜を頂いた三 
菱化成株式会社に深謝致します。

\section{文献}

1) A. W. Prestayko, S. T. Crooke, S. K. Carter (Eds.): "Cisplatin: Current Status and New Developments", (1980), (Academic Press, New York).

2) Y. Chang, L. A. Sternson, A. J. Repta : Anal. Lett., 11B, 449 (1978).

3) C. M. Riley, L. A. Sternson, A. J. Repta: J. Pharm. Sci., 72, 351 (1984).

4) C. M. Riley, L. A. Sternson, A. J. Repta : J. Chromatogr., 217, 405 (1981).

5) P. J. Parsons, A. F. LeRoy: J. Chromatogr., 378, 395 (1986)

6) S. J. Bannister, L. A. Sternson, A. J. Repta: J. Chromatogr., 273, 301 (1983).

7) K. C. Marsh, L. A. Sternson, A. J. Repta : Anal. Chem., 56, 491 (1984).

8) R. A. Baumann, C Gooijer, N. H. Verthorst, R. W. Frei, I. Klein, W. J. F. van der Vijgh : J. Pharm. Biomed. Anal., 5, 165 (1987).

9) R. Kizu, S. Higashi, M. Miyazaki: Chem. Pharm. Bull., 33, 4614 (1985).

10) R. Kizu, K. Hayakawa, M. Miyazaki : Biomed. Chromatogr., 3, 14 (1989).

11) K. A. Jenzen : Z. Anorg. Allg. Chem., 225, 97 (1935).

12) K. A. Jenzen: Z. Anorg. Allg. Chem., 229, 225 (1936).

13) H. J. S. King: J. Chem. Soc., 1338 (1938).

14) S. C. Dhara : Indian J. Chem., 8, 143 (1970).

15) M. J. Cleare, J. D. Hoeschele : Bioinorg. Chem., 2, 187 (1973).

16）宮崎元一, 早川和一: “新しいイオンクロマトグラ フィーの手ほどき”,(1986), (南江堂).
角

Retention behavior of an antitumor platinum complex Cisplatin on ion exchangers. Ryoichi Kizu and Motoichi Miyazaki (Faculty of Pharmaceutical Sciences, Kanazawa University, 13-1, Takara-machi, Kanazawashi, Ishikawa 920)

The novel aspects of Cisplatin, a potent antitumor platinum complex, on HPLC with ion exchange columns were studied. Although Cisplatin is an inorganic nonionic complex, it was retained on both anion and cation exchange columns, but not on reversed-phase columns. The capacity factor was larger on a column with higher ion exchange capacity; a capacity factor of more than 30 was obtained in a system composed of anion exchange MCI GEL CAIOS column and sodium dihydrogen phosphate eluent. However, the capacity factor measured on a column using the appropriate salt solution as the eluent was not affected by changing the concentration or $\mathrm{pH}$ of the eluent. The effect of UV absorptivity of an eluent on the peak height of Cisplatin was studied at various wavelengths in order to confirm the absence of an ion-exchange sorption mechanism in the eluent. No difference was observed between the relative peak height-detection wavelength profiles obtained with UV absorbing eluents and those obtained with UV-non absorbing eluents. These results indicated that Cisplatin might not be retained by ion exchange mechanism, but by other mechanisms such as ion-dipole interactions between Cisplatin and the functional groups of the stationary phases.

(Received December 28, 1989)

\section{Keyword phrases}

Cisplatin; platium(II) complex; antitumor agent; HPLC. 